\title{
The PCL as a brief screen for posttraumatic stress disorder within schizophrenia
}

Article

Accepted Version

Steel, C., Doukani, A. and Hardy, A. (2017) The PCL as a brief screen for posttraumatic stress disorder within schizophrenia. International journal of psychiatry in clinical practice, 21 (2). pp. 148-150. ISSN 1471-1788 doi:

https://doi.org/10.1080/13651501.2016.1271897 Available at https://centaur.reading.ac.uk/68363/

It is advisable to refer to the publisher's version if you intend to cite from the work. See Guidance on citing.

To link to this article DOI: http://dx.doi.org/10.1080/13651501.2016.1271897

Publisher: Taylor \& Francis

All outputs in CentAUR are protected by Intellectual Property Rights law, including copyright law. Copyright and IPR is retained by the creators or other copyright holders. Terms and conditions for use of this material are defined in the End User Agreement.

www.reading.ac.uk/centaur 
Central Archive at the University of Reading

Reading's research outputs online 
The PCL as a brief screen for Posttraumatic Stress Disorder within Schizophrenia

Short Title: PCL as a screen for PTSD in schizophrenia

$$
\text { Craig Steel }{ }^{1}, \text { Asmae Doukani }^{2} \text { and Amy Hardy }{ }^{3}
$$

${ }^{1}$ Department of Psychology, School of Psychology and Clinical Language Sciences, University of Reading, Reading, RG6 6AL, U.K.

${ }^{2}$ Department of Population Health, London School of Hygiene \& Tropical Medicine, London, U.K.

${ }^{3}$ Department of Psychology, Institute of Psychiatry, Psychology \& Neuroscience, London, U.K.

Corresponding Author:

Craig Steel,

Department of Psychology,

School of Psychology and Clinical Language Sciences,

University of Reading,

Reading, RG6 6AL, U.K.

Tel: +004401183787550

Fax: +004401183786715

E-mail: c.steel@reading.ac.uk 


\begin{abstract}
Objectives: To assess the utility of using the Posttraumatic Checklist (PCL) as a screening measure for identifying posttraumatic stress disorder (PTSD) in individuals diagnosed with a psychotic disorder.

Methods: The PCL was administered to 165 participants as part of a clinical trial. Those scoring 44 or above on the PCL underwent further assessment using the Clinician Administered PTSD Scale (CAPS-S).

Results: Overall $18.2 \%$ of the sample exhibited a diagnostic level of PTSD symptoms, as indicated by the CAP-S assessment. Only $29.7 \%$ of those who scored above the PCL threshold were diagnostic of PTSD.

Conclusions: The use of PCL for identifying PTSD within this population is not recommended.
\end{abstract}

Keywords: posttraumatic stress disorder; schizophrenia; assessment; trauma; psychosis. 


\section{Objectives}

Recent studies have highlighted the prevalence of stressful and traumatic life events within individuals diagnosed with a psychotic disorder (Grubaugh et al., 2011). The prevalence of posttraumatic stress disorder (PTSD) as a co-morbid condition within this group has been estimated to be $12.4 \%$ (Achim et al., 2011). These studies have facilitated our understanding of psychotic symptoms within the context of traumatic events (e.g. Longden et al., 2012; Steel et al., 2005) and in the development of trauma-focused treatments for this population (Frueh et al., 2009; van den Berg et al., 2015). Epidemiological findings and therapeutic developments have contributed to recent calls for more trauma-informed mental health services (Rose et al., 2012), including the routine assessment of trauma history and current symptoms of posttraumatic stress. There is, therefore, a need for a brief screening instrument to identify those requiring trauma focussed interventions.

Self-report measures of PTSD have acceptable psychometrics, in comparison to standardised interviews, within non-psychotic populations and can be used in routine clinical practice (Brewin, 2005). However, potential limitations include respondents misunderstanding items and not discriminating accurately between PTSD symptoms and other difficulties (McDonald \& Calhoun, 2010). These limitations may be particularly marked in the context of psychosis. There is considerable overlap between symptoms of psychosis and PTSD, with sensory-perceptual intrusions, hyperarousal, avoidance and dissociation common in both groups. During assessment, additional prompts may be needed to distinguish them from each other (Gearon et al., 2004). Even with prompting, respondents with psychosis may find it difficult to identify symptoms as being temporally anchored to a 
specific traumatic event. Further, the content of psychotic symptoms can be of such a threat so as to constitute a traumatic event itself (Berry et al., 2013). Assessment for the symptoms of post-psychotic PTSD requires careful discrimination from other current symptoms of psychosis, which is not addressed in current self-report measures of PTSD.

The Posttraumatic Checklist (PCL; (PCL; Weathers et al., 1993) is a widely used self-report screening assessment of PTSD. However, there are no reports assessing its reliability in people with psychosis. Mueser et al. (2001) found moderate to high convergent reliability of the PCL and Clinician Administer PTSD Scale (CAPS) in a sample ( $\mathrm{n}=30)$ with severe mental illness. However, only $27 \%$ of their sample had a diagnosis of schizophrenia. The current study reports data from a randomised controlled trial where a PCL cut-off score of 44 is used to indicate more detailed assessment through clinical interview. Previous research has shown the PCL to be $80 \%$ predictive of diagnostic status when using a threshold of 44 in individuals who have suffered a road traffic accident (Blanchard et al., 1996). The design of the parent study required that individuals who scored below PCL cut-off did not undergo further trauma assessment. Therefore, whilst this study is the first to explore the utility of the PCL in identifying PTSD within individuals diagnosed with a psychotic disorder, we limit our focus to the rate of false positives rather than false negatives.

\section{Material and Methods}

\section{Participants}


The current data was obtained as part of recruitment for a randomised controlled trial aimed at evaluating cognitive behaviour therapy as a treatment for the symptoms of posttraumatic distress within individuals diagnosed with a psychotic disorder (ISRCTN67096137).

Inclusion criteria were a current DSM-IV (APA, 1994) diagnosis of schizophrenia, schizoaffective disorder or schizophreniform disorder, being aged between 18 and 65 , able to speak English and having stable living arrangements. Two-hundred and nine individuals

provided informed consent to participate in the clinical trial, of whom 165 provided complete data sets in relation to assessment of traumatic symptoms.

\section{Measures}

Posttraumatic Stress Disorder Checklist (PCL; Blanchard et al., 1996). PCL part I was used to assess the prevalence of a range of traumatic life events. The original 16 items were extended to include two extra items relevant to the current population. Namely, the experience of threatening psychiatric treatment and the experiences of threatening psychotic experiences (Picken \& Tarrier, 2011). Part II of the PCL contains 17 items on a 5-point scale (range 17-85) as brief measure of posttraumatic stress symptoms.

Clinician Administered PTSD Scale for Schizophrenia (CAPS-S; Gearon et al., 2004). The CAPS is a widely used clinical interview based on the DSM diagnostic criteria for PTSD. The CAPS-S is an adapted form of the CAPS (Blake et al., 1995) in which language has been amended for the target population.

\section{Procedure}


Participants first completed PCL part I where they reported which of the 18 stressful life events they had experienced, followed by identifying which of these events was causing them the most current distress. Part II of the PCL was then completed in relation to this item. If a participant scored 44 or above on part II of the PCL, further assessment was conducted using the CAPS-S.

\section{Results}

The 165 participants included 118 (71.5\%) males and 47 (28.5\%) females, and had a mean age of $41.85(S D=10.05)$. The primary diagnosis was schizophrenia for $137(83.0 \%)$ participants and schizoaffective disorder for 28 (17.0\%). Eighty (48.5\%) participants lived alone, $54(32.7 \%)$ with a partner or family and $31(18.7 \%)$ in shared or temporary accommodation. Ethnicity was stated as White 112 (67.9\%), Black Carribbean 6 (3.6\%), Black African 8 (4.8\%), Indian 10 (6.1\%), Pakistani 6 (3.6\%), Bangladeshi 3 (1.8\%), Chinese $1(0.6 \%)$ and Other $16(9.7 \%)$.

The assessment of trauma prevalence and the currently most distressing event is

presented in Table 1. The mean number of stressful life events identified was 5.7 ( $S D=2.9$, range $=1$ to 15 ).

Insert Table 1 About Here 
One hundred and one participants $(61.2 \%)$ scored 44 or above on part II of the PCL in relation to their currently most distressing event, with the mean total being 49.6 ( $S D=17.1$, range $=17$ to 85$).$ Of these $101,30(18.2 \%$ of the total sample $)$ were rated as suffering from a diagnostic level of PTSD based on the CAPS-S assessment. Therefore, only $29.7 \%$ of the sample identified by using the PCL with this cut-off score were diagnostic of PTSD, with $70.3 \%$ being 'false positives'

When the cut-off score on the PCL was raised to 50 or above, 81 (49.1\% of the total sample) participants were included. Of these 81,28 (16.9\% of the total sample) were rated as suffering from a diagnostic level of PTSD based on the CAPS-S assessment. Therefore, only $34.6 \%$ of the sample identified by using the PCL with this cut-off score were diagnostic of PTSD, with $65.4 \%$ being 'false positives'. The total PCL score was significantly correlated with the total CAPS-S score $\left(r_{s}=0.40, p<0.01\right)$

\section{Discussion}

We identified $18.2 \%$ of our sample as exhibiting diagnostic levels of PTSD when using the PCL with a cut-off score of 44, followed by further assessment with CAPS-S. However, if we had adopted a cut-off of 44 on the PCL alone as a diagnostic indicator, $61.2 \%$ of the sample would have been deemed to suffer from PTSD. This figure drops to $49.1 \%$ when using a PCL cut-off score of 50. Our results clearly indicate a large, and clinically unacceptable, number of false positives to occur when using this brief trauma screen to assess posttraumatic symptoms in a sample of people diagnosed with a psychotic disorder. The fact that the CAPS-S is based on clinical interview and not self-report is likely to be 
relevant. Further, anecdotal reports from those conducting the assessments suggest respondents found it difficult to distinguish their psychotic and PTSD symptoms, particularly in relation to psychosis-related traumas.

A clear limitation of the current study is that not all participants were assessed using the CAPS-S. Thus, we do not have complete data on false negatives. That is, there are likely to have been individuals scoring under 44 on the PCL who were exhibiting diagnostic levels of PTSD. Within the psychiatric system this would result in individuals requiring a trauma treatment being missed. However, this group is likely to be small given that only two participants from one-hundred and sixty-five scored between 44 and 50 on the PCL and subsequently revealed diagnostic levels of PTSD. Further, the clinical utility of the use of the PCL within this population is highly questionable based on the data from false positives alone.

Our results have clear implications for the assessment of traumatic symptoms for the purpose of planning interventions within the psychiatric system. The CAPS-S is a detailed clinical interview which requires extensive training for those delivering it, and is unlikely to be widely adopted within routine clinical services. However, although further evaluation of the PCL is required in order to determine sensitivity and specificity, our findings suggest that the PCL is not recommended as a screening tool for PTSD within people diagnosed with a psychotic disorder. Other measures, such as the Trauma Screening Questionnaire (Brewin et al., 2002; de Bont et al 2015) may enable clearer distinction between the self-report of the symptoms associated with PTSD and those associated with a diagnosis of schizophrenia. 


\section{Key Points}

- There have been recent calls for trauma-informed mental health services, including routine assessment of the symptoms of posttraumatic stress disorder in individuals diagnosed with a psychotic disorder.

- Assessment of PTSD within those who have suffered a psychotic episode requires careful distinction between the symptoms of the two disorders.

- The PCL is a convenient self-report measure of trauma symptoms. However, our findings indicate that this instrument is not recommended as a screening tool for PTSD within individuals diagnosed with psychotic disorders.

- Future research should aim to understand why self-report measures are not a valid diagnostic measure of PTSD for this group.

- Based on this understanding, there is the need to develop a brief assessment of PTSD for use in clinical practice.

\section{Declaration of Interest}

The authors do not have any conflict of interest to report regarding this study. This article presents independent research funded by the National Institute for Health Research (NIHR) under its Research for Patient Benefit (RfPB) Programme (Grant Reference Number PB-PG1207-15077). The views expressed are those of the authors and not necessarily those of the NHS, the NIHR or the Department of Health. 


\section{References}

Achim A, Maziade M, Raymond E, Olivier D, Mérette C, Roy M. 2011. How prevalent are anxiety disorders in schizophrenia? A meta-analysis and critical review on a significant association. Schizophr Bull 37:811-821.

American Psychaitric Association. 1994. Diagnostic and statistical manual of mental disorders $\left(4^{\text {th }}\right.$ ed.) Washington DC.

Berry K, Ford S, Jellicoe-Jones L, Haddock G. 2013. PTSD symptoms associated with the experiences of psychosis and hospitalisation. Clin Psychol Rev 33:526-538.

Blake DD, Weathers FW, Nagy LM, Kaloupek DG, Gusman FD, Charney DS, et al. 1995. The development of a clinician-administered PTSD scale. J Trauma Stress 8:75-90.

Blanchard EB, Jones-Alexander J, Buckley TC, Forneris CA. 1996. Psychometric properties of the PTSD Checklist (PCL). Behav Res Ther 34:669-673.

Brewin CR. 2005. Systematic review of screening instruments for adults at risk of PTSD. J Trauma Stress 18:53-62.

Brewin CR, Rose S, Andrews B, Green J, Tata P, McEvedy C, et al. 2002. Brief screening instrument for posttraumatic stress disorder. B J Psychiatry 18:158-162.

De Bont P, van den Berg D, van der Vleugel B, de Roos C. de Jongh A, van der Gaag M, et al. 2015. Predictive validity of the Trauma Screening Questionnaire in detecting posttraumatic stress disorder in patients with psychotic disorders. B J Psychiatry 206:408-416.

Frueh BC, Grubaugh A, Cusack KJ, Kimble MO, Elhai JD, Knapp RG. 2009. Exposurebased cognitive behavioral treatment of PTSD in adults with schizophrenia or schizoaffective disorder: A pilot study. J Anxiety Disord 23:665-675.

Gearon JS, Bellack A, Tenhula WN. 2004. Preliminary Reliability and Validity of the Clinician-Administered PTSD Scale for Schizophrenia. J Consult Clin Psychol 72:121-125.

Grubaugh AL, Zinzow HM, Paul L, Egede LE, Freuh BC. 2011. Trauma exposure and posttraumatic stress disorder in adults with severe mental illness: A critical review. Clin Psychol Rev 31:883-899.

Longden E, Corstens D, Escher S, Romme M. (2012). Voice hearing in a biographical context: A model for formulating the relationship between voices and life history.

Psychosis, 4, 224-234.

MacDonald SD, Calhoun PS 2010. The diagnostic accuracy of the PTSD checklist: a critical review. Clin Psychol Rev 30:976-987. 
Mueser KT, Salyers MP, Rosenberg SD, Ford J. D, Fox L, Carty P. 2001. Psychometric evaluation of trauma and posttraumatic stress disorder assessments in persons with severe mental illness. Psychol Assess 13:110-117.

Picken A, Tarrier N. 2011. Trauma and comorbid posttraumatic stress disorder in individuals with schizophrenia and substance abuse. Compr Psychiatry 52:490-497.

Rose S, Freeman C, Proudlock S. 2012. Despite the evidence - why are we still not creating more trauma informed mental health services. J Public Mental Health 11:5-9.

Steel C, Fowler D, Holmes EA. 2005. Traumatic intrusions in psychosis: an information processing account. Behav Cog Psychother 33:139-152.

Van den Berg D, de Bont PA, van der Vleugel BM, de Roos C, de Jongh A, van Mimnnen A. et al. 2015. Prolonged exposure vs eye movement desensitization and reprocessing vs waiting list for posttraumatic stress disorder in patients with a psychotic disorder: a randomized clinical trial. JAMA Psychiatry 72:259-267.

Weathers FW, Litz BT, Herman DS, Huska JA, Keane TM. 1993. The PTSD Checklist (PCL): Reliablity, validity, and diagnostic utility. Paper presented at the 9th Annual Conference of the ISTSS, San Antonio. 
Table 1: Prevalence of stressful events and currently most distressing event $(N=165)$

\begin{tabular}{|l|c|c|}
\hline & $\begin{array}{c}\text { Percentage events } \\
\text { identified }\end{array}$ & $\begin{array}{c}\text { Percentage identified } \\
\text { as currently most } \\
\text { distressing event }\end{array}$ \\
\hline 1. Motor vehicle accident & $29(17.6 \%)$ & $4(2.4 \%)$ \\
\hline 2. Any other accident & $22(13.3 \%)$ & $0(0.0 \%)$ \\
\hline 3. Warfare or combat & $7(4.2 \%)$ & $2(1.2 \%)$ \\
\hline 4. Death of a close friend or loved one & $107(64.8 \%)$ & $31(18.8 \%)$ \\
\hline 5. Being robbed / present during robbery & $34(20.6 \%)$ & $1(0.6 \%)$ \\
\hline 6. Hit or beaten up by a stranger & $75(45.5 \%)$ & $9(5.5 \%)$ \\
\hline 7. Seeing a stranger attack someone & $40(24.2 \%)$ & $0(0.0 \%)$ \\
\hline 8. Threatened with death / harm & $75(45.5 \%)$ & $10(6.1 \%)$ \\
\hline 9. Childhood Physical Abuse & $57(34.5 \%)$ & $5(3.0 \%)$ \\
\hline 10. Witness Domestic Violence as a Child & $62(37.6 \%)$ & $1(0.6 \%)$ \\
\hline 11. Domestic Abuse & $46(27.9 \%)$ & $5(3.0 \%)$ \\
\hline $\begin{array}{l}\text { 12. Sexual relations before 16 years with } \\
\text { someone 5yrs older }\end{array}$ & $37(22.4 \%)$ & $9(5.5 \%)$ \\
\hline $\begin{array}{l}\text { 13. Sexual abuse before 16 years by } \\
\text { someone of same age }\end{array}$ & $28(17.0 \%)$ & $1(0.6 \%)$ \\
\hline 14. Sexual abuse after 16 & $24(14.5 \%)$ & $11(6.7 \%)$ \\
\hline 15. Being Stalked & $52(31.5 \%)$ & $7(4.2 \%)$ \\
\hline 16. Other Trauma & $69(41 . \%)$ & $39(23.6 \%)$ \\
\hline 17. Threatening psychiatric treatment & $83(50.3 \%)$ & $7(4.2 \%)$ \\
\hline 18. Threatening experiences of psychosis & $105(63.6 \%)$ & $23(13.9 \%)$ \\
\hline
\end{tabular}

